\title{
Innovative Apprenticeship in Qingyuan Polytechnic
}

\author{
Pengfei Zhao \\ Qingyuan Polytechnic, Qingyuan city, Guangdong, China
}

Gan Wei

Wisetronic Inc, Markham, Ontario, Canada

\begin{abstract}
With the practice in Qingyuan Polytechnic as an example, the paper analyzes the innovative apprenticeship home and abroad, and explains the detail information of its characteristics. Respectively they are enterprise dual education, interactive training, on-the-job training, apprentice dual identity, alteration between working and studying, and being successful at work. By discussing the benefits and functions for the government, the enterprise, the school, and the apprentice, the paper brings forward the required connotation for the practice. It also offers suggestions on solving the problems of practicing the apprenticeship.
\end{abstract}

KEYWORD: the innovative apprenticeship; apprentice, personnel training; dual education; dual identity

\section{INTRODUCTION}

After decades of hard work and practice, the vocational education in China made great achievements and made a great contribution to the social development. With the gradual ending of population bonus, the extentive economic growth leads to some problems with the ecological environment and natural resources. The transformation of social economy, the promotion of industrial structure, and technology upgrading are badly needed for the economic growth in China. All the elements lead to tremendous changes with the demand of talents. In order to deal with the changes of the demanded talent, the current vocational education has to adjust the process of the personnel training and development. The innovative apprenticeship is one of the best choices for the adjustment. This is also an important measure for vocational schools accommodate the regional social development and economic growth.

\section{ANALYSIS ON PRESENT SITUATION}

Traditional apprenticeship is a system of training a new generation of practitioners with a basic set of skills. Innovative Apprenticeship integrates the traditional one with the updated educational theories, which advocate the co-op between enterprises and vocational schools. As a new style of personnel training, its basis is co-op, and its core is the combination between work and study. Its distinctive features are enterprise dual education and apprentice dual identity. The enterprise dual education means that the enterprise will not only make use of personnel, it also educates personnel. It regards the enterprise as an important element for vocational education, combining producing and teaching. The training is planned while working for an employer, while the learners enjoy the benefit of the enterprise. At the same period of field work, the theoretical education is also involved. After World War II innovative Apprenticeship has been the main pattern of the vocational education for the western advanced countries. This fosters their rapid social development and economical growth. Considering its advantage, Chinese vocational schools are practicing the innovative apprenticeship based on the regular co-op programs.

\subsection{Present situation of the international innovative Apprenticeship}

The innovative Apprenticeship is originated in the Federal Republic of Germany's occupation training after World War II. Being the main pattern of the vocational education, it matches with the national system and the education system, resulting the rapid social development and economical growth in the Federal Republic of Germany. Then its success is recognized by many other countries. Today the western advanced countries highly emphasize the innovative Apprenticeship. By the support of European Union, in 2006 INAP (International Network of Innovative Apprenticeship) was found 
by experts and scholars from different universities and institutions all around the world. According to its studying, the innovative apprenticeship changes a lot in different countries with different culture backgrounds.

Based on the personnel training and practicing, the innovative apprenticeship has four typical forms in the western advanced countries. The first one is the model named Modern Apprenticeship in British. The Government introduced Modern Apprenticeships in 1994. Employers who offer apprenticeship places have an employment contract with their apprentices, but off-the-job training and assessment is wholly or partly funded by the state for apprentices. For example, in England the government only contributes $50 \%$ of the cost of training for apprentices aged $19-24$, and employers of apprentices over the age of 25 may get only a contribution. During the process, there is an alteration between work and study. The apprentices work for the employer and then go back school. The cycle may repeat several times. It takes advantages of both schools and field training. The second one is Australian model. The model has been founded since 1970s. Australian apprenticeship covers all industry sectors in Australia and is used to achieve both 'entry-level' and career 'up-skilling' objectives. Australian apprenticeship can be full-time, part-time or school-based. Australian State and Territory Governments may provide public funding support for the training element of the initiative. In Australia, apprentices and trainees spend $80 \%$ of the time working for the employers, and $20 \%$ of the time studying in TAFE (Technical And Further Education). Its curriculum pays attention to both the professionalism and the practicality, integrating the field work with classroom teaching. The third model of innovative apprenticeship is in Switzerland. It looks similar to Germany and Austria. But it is ternar, integrating enterprise, school and industry training center together. The enterprise provides the apprentice position. The school and industry training center set up teaching standard and both train apprentices. The training quality is supervised by the industry. For the apprentices, they need to spend 1 or 2 days a week in school studying general courses and theory knowledge, and 3 or 4 days a week in enterprise working as regular staffs. They also need to spend 1 or 2 weeks a term in industry training centers studying cross-industry knowledge, as a supplement to what seems insufficient from the enterprise and school. Here the industry has been considered as an important element for the personnel training. The fourth one is the Co-op model in U.S.A., which is very popular for combining work with learning. The apprentice has to achieve ability objectives set by the specific industry. And the ability objectives may be divided into several subobjectives. For example, the construction industry is perhaps the heaviest user of apprenticeship programs in the United States. Most of these apprentices participated in what are called "joint" apprenticeship programs, administered jointly by construction employers and construction labor unions. The International Union of Painters and Allied Trades (IUPAT) have founded the Finishing Trades Institute (FTI). And the FTI works towards national accreditation to offer associate and bachelor degrees, integrating academics with a more traditional apprentice programs. With the co-op model, the apprentice has much more choices for their study and work. With this co-op mode, the apprentice, education service provider and enterprise are partners together, but with its own specific responsibility.

Being the main pattern of the vocational education for the western advanced countries, the innovative apprenticeship is not static. It is dynamic but it is originally based on the German "Dual System". National law and policy are the fundamental guarantee of the innovative apprenticeship so that both the enterprise and school can work actively together for the whole process of personnel training.

\subsection{The innovative apprenticeship in China}

With requirements from both the social development and the development of vocational education, many Chinese schools work hard with different forms of the innovative apprenticeship. Here are some examples. In 2006 CSIT (Chien-shiung Institute of Technology) in Jiangsu province worked together with enterprises in Germany. It tried a form named dual system of fixed position and customized the localization. In 2010 the Xinyu city in Jiangxi province set up the experiment base of Xinyu innovative apprenticeship. In 2011 Beichang Advanced Vocational School in Jiangsu began its own apprenticeship with secondary-level vocational education. Guangzhou Technician School began non--academic training for its mechanic education. All these examples obtained some success and gathered some experience.

Comparing with the practice in western advanced countries, the innovative apprenticeship in China is still in the primary stage. First, although the state and local governments emphasize vocational education, there is no specific law and policy to support the apprenticeship. Second, the dual identity is not realized legally for school-based apprentices. Third, vocational training and non-academic education can not go together effectively. Fourth, the innovative apprenticeship in China can not totally satisfy the human resource market. It also can not satisfy all for both the enterprise and the apprentice. This is the reason not to fully bring the enthusiasm of the enterprises with the practice of apprenticeship. 


\section{THE PRACTICE IN QINGYUAN POLYTECHNIC}

As a vocational school in South China, Qingyuan Polytechnic began co-op between school and enterprise ten year ago. The three stages since then are internship, order training, and co-op training base. Today the innovative apprenticeship is the focus of the school. Now it is the main pattern for personnel training in the school. The co-op style has been developed from the loose stage to the close stage. During the practice, we have a lot of surveys with the well-known enterprises to see how to fully satisfy their requirements. According to the survey, there are many different factors showed that, after 30 years economic reforming in Guangdong province, the enterprises have to upgrade themselves because of the social development. This includes not only the transformation of social economic, but also the structural adjustment and the technological upgrading, which change the requirement of the human resource. A great many enterprises realize the change and they have active plans of on-the-job training and continued education. In order to solve the problems of their employment and technicians training, some large-scale enterprises voluntarily work together with the polytechnic. All these elements urge the school to work hard with innovative apprenticeship.

\subsection{The practice of the apprenticeship in the school}

Considering different enterprises, professional characteristics, and school enrollment, the school have co-op with hi-tech enterprises, modern manufacturing enterprises, and service industry enterprises. Following are the three kinds of co-op with the apprenticeship.

\section{(i) The interactive co-op with hi-tech enterprises.}

Recently the hi-tech enterprises develop rapidly with the adjustment of industrial structure. The development is so fast that is hard for the system of personnel training in schools to follow. Schools can not provide enough personnel for hi-tech enterprises. The first reason is that hi-tech enterprises like to keep their business secrets and technology secrets. It is impossible for the schools to share the updated information to train their students. The second reason is that technology renews faster that ever before. The graduates from technology schools have to learn much more knowledge than the graduates decades ago. This is hard for teacher and students. Normally the hi-tech enterprises ask their new employees to become skill workers in less than 1 year. The training for the change is difficult and costly, not only to the enterprise but also to the schools.
According to the requirements, Qingyuan Polytechnic has a co-op with Yulong Telecommunication Ltd., which is a leading enterprise of smart phone in China. We both agree to the training plan with the game development for mobile phones. After the national university entrance examination, students go to the school and there is a three party agreement signed by the students, the enterprise, and the school. The school and the enterprise work together to meet the urge need of personnel training for software developing \& testing.

For the first two school years, the curriculum is set mainly by the industry standard provided by the school and the enterprise. The school teaching includes books knowledge and basic skill. For the first 1 and half years engineers of the company teach some subjects about the enterprise culture and skill practice, and another half year the engineers teach students internship skill. In the third school year, the students have to sign an internship agreement with the company, enjoying all the same benefit as the normal employees. Based on the requirements of specific positions and the unique situation of students, the company chooses their best technicians as the mentors for the students. Then there is a specific training plan for the one-on-one mentoring. The company periodically evaluates the effect of the training to achieve the expected goal. At the same time full-time teachers from the school work together with the students. When finding something new to students, they will teach the new theory to the students at nights or on weekends. In accordance with the standard of the industry, the school will accept the company evaluation as the academic achievement for students, and the students can work for the company after they graduate.

After years of hard work, three batches of Yunlong Innovative Apprenticeship Class graduate from the school and become the main force of the company. Some of them are elevated to administrators. And 12 of them have applied 22 national patents for their inventions. Now the company actively takes part in the innovative apprenticeship because it recognizes that the plan can solve the shortage problem of high-tech talent, which bothering the company for a long time.

(ii) The on-job training for manufacturing and service industry.

With the enterprise transforming, there is talent shortage with the manufacturing and service industry. On one hand the industry needs a lot of skilled workers for their front-line positions. On the other hand a lot of worker with low education and low skills face unemployment, even though the companies do not want to lose some experienced workers. And the workers look forward to improve themselves. For the personnel shortage problem, Hailuo Cement Co. Ltd in Yingde city and Elizabeth 
beauty and fitness Co. Ltd in Guangzhou city take the initiative of personnel training with Qingyuan Polytechnic.

By the autonomous enrollment, the current workers in the enterprises become students directly so the apprentices naturally have dual identity, including the student and staff identity. The personnel training program and the curriculum are developed by both sides. The teams of teachers and mentors are also appointed by both sides. The apprentices get on-duty training. This is called alternation between work and study, merging together with the administration of the enterprises and the school.

During the practice, Hailuo Cement Co. Ltd gets skilled labor. It is the multi-wins for the enterprise, the school, and the staffs. The enterprise improves comprehensive competitiveness when the staffs improve their quality, after the staffs raise their sense of identification and belonging with the enterprise. The school can service the community better and more. The staffs are more confident with their future. Elizabeth beauty and fitness Co. Ltd also realizes the alternation co-op is a good path for the vocational education.

(iii) The alternation co-op with other industries

The Aluminum Association in Foshan city is one of the biggest among the Chinese NGO (NoneGovernment Organization). It products more than $30 \%$ of the national annual production. Meiya Aluminum Co. Ltd in Qingyuan city is one of it largest branches. It needs to upgrade itself by technology.

In 2012 the company and the school signed a coop agreement for the innovative apprenticeship. The school enrolls perspective apprentices from the secondary vocational students and then the apprentice gets dual identity automatically. Considering industry standard, the occupation qualification standard, and the enterprise requirement, the personnel training program is developed by both sides, the apprentices are educated by both sides. In the first school year, students study basic theory knowledge. They also practice field work. In the year the enterprise sends advanced administrators and skilled worker to teach subjects related to the enterprise background. In the second year the enterprise find the right position and mentor for every apprentice. The on-duty training is evaluated by the enterprise standard. During the training, the apprentices have the same benefit as the staffs and they make decisions for their future careers. This model of innovative apprenticeship tries the best for the enterprise to educate its required talents. And it may provide talents for small businesses without their own mentors and talents.

\subsection{Achievements and problems with the apprenticeship}

(i) The achievements

By the co-op of both the enterprise and the school, we draw the preliminary conclusion that the model of the innovative apprenticeship needs to change with different enterprises, different enrollments, different apprentices so that the right personnel can be provided for the human resource market. The practice is highly appreciated by the co-op enterprises. The first reason is that the apprenticeship provides their required talents. The second reason is that it is a multi-win for the enterprise, the school and the staffs. The third reason is that the enterprises have the same idea of personnel training as the school. And this helps each other create a long-term co-op.

\section{(ii) The problems.}

The first problem is the residence registration for the apprentices. According to the policy of Chinese autonomous enrollment, without local residence, the perspective apprentices are not allowed to take the entrance examination and then study in the school. In Guangdong province $80 \%$ of the employees do not have the local residence. It means they do not have the opportunity to become the apprentices in the local vocational schools. And it is impossible for the enterprises improve their staffs quality. The enterprises may lose enthusiasm with the apprenticeship.

The second problem is the apprentices how to get the dual identity. For getting employee identity for the full-time students, usually an agreement is signed by the apprentices, the enterprise, and the school. Although with the agreement the apprentices are the legal employees, they are not the permanent employees of the enterprise. The dual identity needs to be re-defined according to the international standard and the Chinese reality.

The third problem is how to raise the enthusiasm both for the enterprise and for the school. In China the apprenticeship is still in its beginning stage. During the practice, there are not specific national law and policy to deal with problems for apprentice, the enterprises, and the schools. Especially for the schools and the enterprises, they have to take a lot of challenges and settle a lot of disputes by themselves. This is costly and has negative effect for both sides.

\section{SUGGESTIONS ON THE APPRENTICESHIP}

After a long time hard working, the innovative apprenticeship is regarded as a good thing for both the enterprise and the school. They work together to create the dual education. Vocational education has to follow the enterprise requirements. And 
apprenticeship is one of the best paths for the vocational education to go. We also realize that the fundamental driving force for the apprenticeship is to upgrade labor skills, resulted by the structural variation of human resource market and the movement of labor force. The practice of apprenticeship makes the movement of labor force reasonable, promoting the harmonious development of society. The key to practice apprenticeship is to take care all 4 participators, including the government, the enterprise, the school and the apprentice. And a long term co-op will benefit all the 4 participators.

Following is the table to show the benefit and the function for the 4 participators.

Table 1 The benefit and the function for the 4 participators.

\begin{tabular}{|l|l|l|}
\hline Beneficiary & The benefit & The function \\
\hline Government & $\begin{array}{l}\text { Upgrade the labor quality, promote the harmonious } \\
\text { development of society. }\end{array}$ & $\begin{array}{l}\text { Set specific law and policy to insure the } \\
\text { apprenticeship develops in the right path. }\end{array}$ \\
\hline Enterprise & $\begin{array}{l}\text { Get financial aid from government, get quality and } \\
\text { affordable labor, and get technical support from colleges. }\end{array}$ & $\begin{array}{l}\text { Provide co-op positions \& benefit for apprentices. } \\
\text { Take part in all the process of personnel training. }\end{array}$ \\
\hline School & $\begin{array}{l}\text { Get financial aid from government, share education } \\
\text { resource with enterprises, expense enrollment, and } \\
\text { upgrade education quality. }\end{array}$ & $\begin{array}{l}\text { Organize, coordinate and commit the practice of } \\
\text { innovative apprenticeship. }\end{array}$ \\
\hline Apprentice & $\begin{array}{l}\text { Get financial aid, learn practical skills, and become a } \\
\text { good citizen for the society. }\end{array}$ & $\begin{array}{l}\text { Need to study and work hard to upgrade the } \\
\text { quality. }\end{array}$ \\
\hline
\end{tabular}

Based on the above analyses, two things are needed for the innovative apprenticeship. One is policy and the other is connotation.

\subsection{Suggestions on the policy}

First, specific law and policy for apprenticeship are needed to set up as soon as possible. This is the basic for the innovative apprenticeship. Because the advanced countries are successful with the apprenticeship, we can draw on their experience, such as "the two-element pattern" for vocational education in Germany. The countries have a lot of preferential policies to support the practice. The tax, the insurance, and different kinds of financial aids are visible help to the innovative apprenticeship.

Second, all administrative agents should encourage the experiment of the innovative apprenticeship by funding and policy. And the local government should allocate more educational funds to support the innovative apprenticeship.

Third, the experts of education, law, and public administration have to work together based on the social development. After amending the education and law clauses, the innovative apprenticeship should have a bright future.

\subsection{Suggestions on the connotation}

The school and enterprise have to pay attention to connotation construction based on both co-op. Considering many requirements of dual education, interactive training, on-the-job training, apprentice dual identity, alteration between working and studying, and being successful at work, etc, the followings problems are what we need to take care of when we think about connotation construction.

The problem is how to form an effective team for apprenticeship. The members need to have double qualification. They teach not only book knowledge, but also the knowledge of field work. It is obvious that the team should have a series of ability to do the following jobs, such as analyzing vocational posts, developing vocational curriculum, administrating and accessing apprentices' achievement, etc. All these elements need the teachers in the school have the certificate of field work, and the mentors in the enterprise have the teacher certificate. Furthermore, the school teachers sometimes should work as technicians for the technical support, and the enterprise mentors sometimes teach more subjects than the former. More teachers and mentors are required because there are much more practical subjects for the innovative apprenticeship than traditional education.

The second problem is how to deal with the onduty training problem. It needs the co-op of both sides to decide the method of personnel training, develop the curriculum, evaluate the training effect, and many other things related to the apprenticeship.

\section{CONCLUSION}

Because the personnel training is based on the industrial structure and the enterprise requirements, the innovative apprenticeship can not be copied and transplanted directly for the success. The benefit of the enterprise, the specific law and policy, and something more have to be considered comprehensively. Deepening the co-op with 
enterprises and strengthen the connotation construction for vocational schools are the key to the success of the innovative apprenticeship.

\section{REFERENCES}

[1] The Construction Chart Book: The US Construction Industry and its Workers". CPWR. Retrieved 17 June 2013.

[2] Weiping Shi and Guoqing Xu. The Comparative Study for Vocational Education System in the World. The Forum of Vocation Education. 2004,1:23-25.

[3] Liming Wang. The Trend of the Development of Vocation Education in Western Countries. Occupation Space. 2006, 12: 71-72.

[4] Guo Qing and Xiangyong Liu. The Meaning and Development of Apprenticeship in West Europe. Journal of Hebei Normal University. 2011,11:66-70.

[5] Linna Feng. Study of Security Mechanism for German Vocational Education. Shanxi Normal University, 2010.
[6] Jinji Xu. Compare the Apprenticeship in England and Australia. Journal of Yunnan Normal University. 2007,3:74-77.

[7] Xiaoli Guo. The Enlightenment of Australian Apprienticeship. Journal of Changjiang University. 2010, 2: 337-338.

[8] Zhiqiang Chen. Study of Personnel Training Based on the Dual Education. Vocational and Technological Education. 2010,11:69-7.

[9] Baoli Lu and You Zhao. Research on Culture Transferring for Apprenticeship. Forum of Vocational Education. 2011,28:94-98.

[10] Yan Chen. How to Face Examination. Vocational and Technological Education. 2011,30:6.

[11] Zhiqun Zhao. Integration of Work \& Study and Innovative Apprenticeship. Forum of Vocational Education. 2009,36:3.

[12] Fu Li. The Right Model of Vocational Education for Different Industrial Structure. Journal of Education. 2010, 3: 74. 